\title{
A novel technique for the investigation of corrosion of aluminum beneath organic coatings
}

\author{
Kenzo KOBAYASHI*, Ken-ichi SHIMIZU* \\ and Yasuhiro TSUDA*
}

(Received November 30, 1988)

\section{Introduction}

Corrosion of aluminum in aqueous solutions (mostly in solutions containing $\mathrm{Cl}^{-}$) has been investigated in greater detail by many authors and a considerable amount of data have been accumulated ${ }^{1}$. However, very little is known about the corrosion of aluminum beneath organic coatings, despite its importance not only in understanding the degradation of adhesion between aluminum and organic coatings generally ${ }^{2)}$, but also in the corrosion failure of aluminum-metallized electronic devices ${ }^{3)}$. One of the main difficulties in the study of corrosion of aluminum beneath organic coatings is the lack of techniques for direct observation of corroding aluminum surface beneath organic coatings.

With the advent of improved ultramicrotomy, where thin slices of various metals, about 25-50 nm thick, can be obtained successfully, direct observation of the interface between metals and organic coatings now become reality ${ }^{4}$. The purpose of the present note is to show, by an example, that the direct observation of the aluminum/coating interface alone can provide considerable insight into the nature of corrosion of aluminum beneath organic coatings. The example taken here is the corrosion of epoxy-coated aluminum in a warm distilled water, where corrosion proceeds relatively slowly and where various electrochemical techniques for the study of corrosion of painted metals cannot be applied.

\section{Experimental}

High purity (99.99\%) aluminum sheets of dimensions of $50 \times 10 \times 0.5 \mathrm{~mm}$ were electropolished in a perchloric acid- ethanol bath, rinsed thoroughly in absolute ethanol and, finally, dried in a hot air stream. An epoxy coating was applied by dip coating to all sides of the electropolished specimens and cured at $85^{\circ} \mathrm{C}$ for $2 \mathrm{hrs}$ in an arr-forced oven. The epoxy coating was found to have thickness ranging from approximately 8 to $16 \mu \mathrm{m}$. Permeability of water through the epoxy coating of about $11 \mu \mathrm{m}$ thick, which is close to the average thickness of the coating employed in the present work, has been reported to lie in the range 1-2.4 $\mathrm{mg} / \mathrm{cm}^{2} \cdot \mathrm{hr}^{5)}$. Total of nine epoxy-coated aluminum specimens were immersed in distilled water at $40^{\circ} \mathrm{C}$ for 48 hrs. After the immersion, the test specimens were withdrawn from the distilled water, dried in a cold air stream and, finally cut into small pieces for the preparation of ultramicrotomed sections.

Ultramicrotomed sections of the aluminum substrate and epoxy coating were prepared in the now usual manner using a du Pont Solvall MT 2B ultramicrotome ${ }^{4)}$. In short, the small pieces of test specimens were trimmed initially with a glass knife and suitably thin sections, about $25-50$ $\mathrm{nm}$ thick, were obtained finally by sectioning in a direction approximately parallel to the aluminum-epoxy interface using a diamond knife. The ultramicrotomed sections were examined in a Hitachi HU-12AS transmission electron microscope operated at $100 \mathrm{kV}$.

\section{Results and discussion}

Transmission electron micrographs of ultramicrotomed sections taken through the aluminum-epoxy interface are shown in Figs. 1 and 2. The aluminum substrate is observed at the bottom of each micrograph and shows darker bands or extinction contours that diffract at that particular

\footnotetext{
* Department of Chemistry, Faculty of Science and Technology, Keio University (Yokohama-shi, Kanagawa).
} 

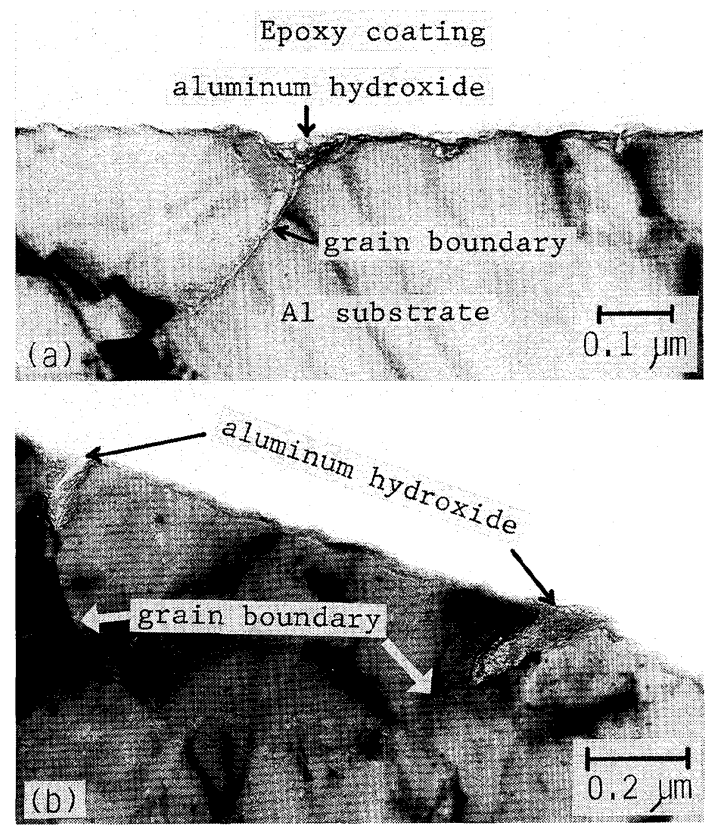

Fig. 1 Transmission electron micrographs of ultramicrotomed sections taken through the aluminum-epoxy interface after the epoxy coated specimens were given $48 \mathrm{hrs}$ immersion in distilled water at $40^{\circ} \mathrm{C}$.

orientation to the electron beam. The epoxy coating is observed to be attached to the aluminum substrate only in Fig. 1-a. Due to lower contrast in the electron microscope, the epoxy coating is observed only faintly at the top of the micrograph. In Figs. 1-b and 2, the epoxy coating was observed to be detached from the aluminum substrate. However, a close examination of the detached slices of the epoxy coating revealed that the original features of the aluminum-epoxy interface were largely retained in these micrographs.

Interesting features are observed at the aluminum-epoxy interface where the grain boundaries intersect the surface (Fig. 1, Fig. 2-a). In such regions, etched grooves are observed. Deposition of porous aluminum hydroxide is also observed inside such grooves. Furthermore, it appears that the etched grooves tend to develop deep into the metal along the grain boundaries (Fig. 1-b). Examination of thousands of slices taken from various regions of the specimens revealed that etched grooves are observed mostly at local regions where the grain boundaries intersect the surface. Most of the remainder surface was found to be covered with a thin hydroxide layer only about $10 \mathrm{~nm}$ thick (Fig. 2-b), although shallow etched grooves were observed occasionally veven in such region.
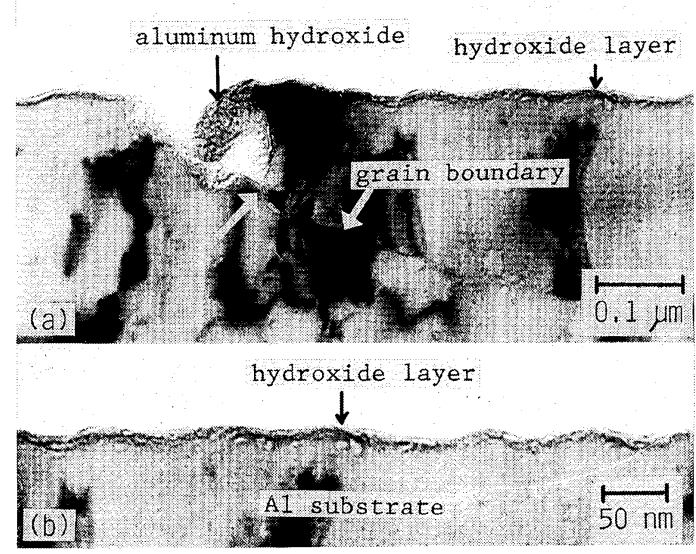

Fig. 2 Cross-section of the aluminum-epoxy interface, showing a pronounced local attack at the grain boundary and a slower attack over the metal grains.

It appears that the corrosion of aluminum beneath the epoxy coating proceeds at much slower rate than in the absence of the coating where, under otherwise similar conditions, aluminum surface has been shown to be covered with hydrous oxide layer thicker than $1 \mu \mathrm{m}^{6)}$. This is thought to be due to the fact that only small amount of water is available at the aluminum-epoxy interface through the epoxy coating. In the presence of the epoxy coating and except for local regions in the immediate vicinity of the grain boundaries, where pronounced local attack was observed, aluminum surface generally is covered with a thin hydroxide layer only about $10 \mathrm{~nm}$ thick. The pronounced local attack along the grain boundaries is not the specific phenomenon associated with the presence of the epoxy coating, but is also observed even in the absence of the epoxy coating during the corrosion of aluminum in distilled water $^{7)}$. This has been ascribed to the increased rate of dissolution of the amorphous aluminum oxide, and hence increased anodic activity, at local regions in the immediate vicinity of the grain boundaries due to high $\mathrm{pH}$ associated with the cathodic activity of the grain boundaries ${ }^{6), 7)}$.

The present results indicate clearly that ultramicrotomy is an extremely useful technique to prepare thin cross-section of the interface between aluminum and organic coatings. Perhaps, the most important and unique advantage of the present technique is that it allows direct observation of the interface between aluminum and epoxy coating at microscopic level that cannot be readily achieved by any other techniques. Another important advantage of the present technique is that it can be applied even in situations where various electrochemical techniques for the study of 
corrosion of painted metals cannot be applied, e.g., corrosion of epoxy-coated aluminum by humidity which is of great practical importance in corrosion failure of aluminum-metallized electronic devices.

\section{Acknowledgements}

Thanks are due to Dr. Y. Fukuda and Dr. T. Fukushima of the National Research Institute for Metals for the provision of time on du Pont Solvall MT 2B Ultramicrotome. Thanks are also due to Dr. H. Tanabe of DAINIPPON TORYO Co. Ltd. for supplying us with the epoxy paint.

\section{References}

1) R. T. Foley: Corrosion, 42 (1986), 277.
2) J. D. Venables: in "Adhesion 7", K. W. Allen ed., pp. 87-93, Applied Science Publishers, Essex, England, 1983.

3) G. L. Schnable, R. B. Comizzoli, W. Kern and C. K. White: RCA Review, 40 (1979), 416.

4) R. G. Furneaux, G. E. Thompson and G. C. Wood: Corros. Sci., 18 (1978), 835.

5) "Adhesion between Organic Coatings and Aluminum and Aluminum Alloys (3rd Report)', Japan Institute of Light Metals, July, 1986, pp. 6-8.

6) R. S. Alwitt: "Aluminum-Water System" in "Oxide and Oxide Films" (J. W. Diggle ed.), Marcel Dekker, New York, pp. 202-247, 1972.

7) W. Vedder and D. A. Vermilyea: Trans. Farad. Soc., 65 (1969), 561. 